\title{
Tomography-based monitoring of isothermal snow metamorphism under advective conditions
}

\author{
P. P. Ebner ${ }^{1,2}$, M. Schneebeli ${ }^{2}$, and A. Steinfeld ${ }^{1}$ \\ ${ }^{1}$ Department of Mechanical and Process Engineering, ETH Zurich, 8092 Zurich, Switzerland \\ ${ }^{2}$ WSL Institute for Snow and Avalanche Research SLF, 7260 Davos-Dorf, Switzerland \\ Correspondence to: A. Steinfeld (aldo.steinfeld@ethz.ch) and M. Schneebeli (schneebeli@slf.ch)
}

Received: 21 January 2015 - Published in The Cryosphere Discuss.: 18 February 2015

Revised: 12 June 2015 - Accepted: 30 June 2015 - Published: 30 July 2015

\begin{abstract}
Time-lapse X-ray microtomography was used to investigate the structural dynamics of isothermal snow metamorphism exposed to an advective airflow. The effect of diffusion and advection across the snow pores on the snow microstructure were analysed in controlled laboratory experiments and possible effects on natural snowpacks discussed. The 3-D digital geometry obtained by tomographic scans was used in direct pore-level numerical simulations to determine the effective permeability. The results showed that isothermal advection with saturated air have no influence on the coarsening rate that is typical for isothermal snow metamorphism. Isothermal snow metamorphism is driven by sublimation deposition caused by the Kelvin effect and is the limiting factor independently of the transport regime in the pores.
\end{abstract}

\section{Introduction}

Snow is a bi-continuous material consisting of fully connected ice and pore space (air) (Löwe et al., 2011). Because of the proximity to the melting point, the high vapour pressure causes a continuous recrystallization of the snow microstructure known as snow metamorphism, even under moderate temperature gradients (Pinzer et al., 2012; Domine et al., 2008). The microstructural changes of snow towards equilibrium under conditions of constant temperature are referred to as isothermal snow metamorphism (Colbeck, 1997a; Kaempfer and Schneebeli, 2007). This is a coarsening process whose driving force is the reduction of the surface free energy of the complex ice-air interface. The energy reduction is caused by mass transport processes such as vapour diffusion (Neumann et al., 2009), surface diffu- sion (Kingery, 1960b), volume diffusion (Kuroiwa, 1961), and grain boundary diffusion (Colbeck, 1997a, 1998, 2001; Kaempfer and Schneebeli, 2007). Viscous or plastic flow (Kingery, 1960a), and sublimation condensation with vapour transport (German, 1996; Hobbs and Mason, 1963; Legagneux and Domine, 2005; Maeno and Ebinuma, 1983) are also suggested to play an important role. The Kelvin effect is seen as the driving force for isothermal snow metamorphism (Bader et al., 1939; Colbeck, 1980). Recent studies indicate that sublimation deposition is the dominant contribution for temperatures close to the melting point, whereas surface diffusion dominates at temperatures far below the melting point (Vetter et al., 2010). Snow has a high permeability, which facilitates diffusion of gases and, under appropriate conditions, airflow (Gjessing, 1977; Colbeck, 1989; Sturm and Johnson, 1991; Waddington et al., 1996). Both diffusion and advective airflow affect heat and mass transports in the snowpack (Cunningham and Waddington, 1993; Albert, 1993; McConnell et al., 1998). In the dry snow zone of an ice sheet, Sowers et al. (1992) described a convective zone located just below the surface in which the air is rapidly flushed by convective exchange with the overlying atmosphere. A rapid decrease of the airflow velocity inside a snow layer $\left(\leq 0.01 \mathrm{~m} \mathrm{~s}^{-1}\right)$ for high wind speed $\left(\approx 10 \mathrm{~m} \mathrm{~s}^{-1}\right)$ above the snow surface (pore size $\approx 1 \mathrm{~mm}$ ) are numerically estimated by Neumann (2003). In addition, Colbeck (1997b) confirmed the rapid decrease of airflow velocities inside a snowpack. Advective flow of air may have a direct effect on snow-air exchange processes related to atmospheric chemistry (Clifton et al., 2008; Grannas et al., 2007), and snow metamorphism (Albert and Gilvary, 1992; Albert et al., 2004), and can change the chemical composition of trapped atmospheric gases in ice cores (Legrand 
and Mayewski, 1997; Neumann and Waddington, 2004; Severinghaus et al., 2010). However, no prior studies have experimentally analyzed the effect of saturated airflow on the vapour transport and the recrystallization of the snow crystals using non-destructive technique in time-lapse experiments. Over- or undersaturated air leads to a rapid growth or shrinkage of snow structures exposed to such conditions, as exemplified in the growth of surface hoar (Stössel et al., 2010). However, saturation vapour density of the air is reached in the pore space within the first $1 \mathrm{~cm}$ of the snow sample, regardless of temperature or flow rate (Neumann et al., 2009; Ebner et al., 2014). The change in shape of the snow crystals during metamorphism also affects the permeability, which, in turn, will continue to affect the shape of the snow structure. Although long-term isothermal metamorphism occurs in nature only in the centre of the polar ice caps (Arnaud et al., 1998), it is important to reduce physical complexity of experiments in order to understand the basic mechanisms governing metamorphism.

The objective of this paper is to study the effect of saturated airflow on the vapour transport and the coarsening rate of snow under isothermal conditions. We designed experiments in a controlled refrigerated laboratory and used time-lapse computed tomography (micro-CT) to obtain the discrete-scale geometry of snow (Schneebeli and Sokratov, 2004; Kaempfer and Schneebeli, 2007; Pinzer and Schneebeli, 2009; Chen and Baker, 2010; Pinzer et al., 2012; Wang and Baker, 2014; Ebner et al., 2014). The extracted 3-D digital geometry of the snow was used to calculate the specific surface area and porosity. Direct pore-level simulations (DPLS) were applied to determine the effective permeability by solving the corresponding mass and momentum conservation equations (Zermatten et al., 2011, 2014).

\section{Methodology}

Isothermal experiments with fully saturated airflow across snow samples were performed in a micro-CT at laboratory temperatures of $T_{\mathrm{lab}}=-8$ and $-15^{\circ} \mathrm{C}$. Figure 1 shows a schematic of the experimental setup (Ebner et al., 2014). It is to be noticed that the accurateness of the isothermal conditions between the top and base of the sample was less than $0.2^{\circ} \mathrm{C}$ and a temperature gradient of about $6.7 \mathrm{~K} \mathrm{~m}^{-1}$ was possible. However, this was still in the uncertainty of the thermistors $\pm 0.2 \mathrm{~K}$ (Ebner et al., 2014) and therefore a quasiisothermal condition was given. Two different snow types with high specific surface area were considered to evaluate the structural change in the earlier stage of isothermal metamorphism of new snow, more in detail. Partly decomposed snow (DFdc) was used for low flow rate ("sa1" and "sa2") whereas large rounded snow (RGlr) was used for higher flow rate ("sa3" and "sa4") to prevent destruction of the fragile snow structure (Fierz et al., 2009). Snow identical to natural snow was used for the snow sample preparation (wa- ter temperature: $30^{\circ} \mathrm{C}$; air temperature: $-20^{\circ} \mathrm{C}$ ) (Schleef et al., 2014). It was sieved with a mesh size of $1.4 \mathrm{~mm}$ into two boxes, and sintered for 13 and 27 days at -15 and $-5^{\circ} \mathrm{C}$, respectively, for increasing strength and coarsening (Kaempfer and Schneebeli, 2007). A cylinder cut out (diameter: $53 \mathrm{~mm}$; height: $30 \mathrm{~mm}$ ) from the sintered snow was filled into the sample holder (Ebner et al., 2014). The snow samples were analysed during $96 \mathrm{~h}$ with time-lapse micro-CT measurements taken every $8 \mathrm{~h}$, producing a sequence of 13 images. Table 1 summarizes the morphological parameters of the snow. Four different runs were chosen based on the Peclet number $\left(P e=u_{\mathrm{D}} d_{\mathrm{p}} / D\right.$ where $u_{\mathrm{D}}$ is the superficial velocity in snow, $d_{\mathrm{p}}$ is the pore diameter, and $D=2.036 \times 10^{-5} \mathrm{~m}^{2} \mathrm{~s}^{-1}$ is the diffusion coefficient of water vapour in air) to compare the advective and diffusive transport rates inside the pore space. Experimental runs were performed at $1 \mathrm{~atm}$ pressure and volume flow rates of 0 (no advection), $0.36,3.0$, and $5.0 \mathrm{~L} \mathrm{~min}^{-1}$, corresponding to $P e=0$, $0.05,0.47$, and 0.85 . Higher $P e$ numbers were experimentally not possible, as the shear stress due to airflow could destroy the snow structure, and we restricted the flow rate to the corresponding maximum $P e \approx 0.8$ extracted from the simulations of Neumann (2003) and Colbeck (1997b). Assuming an isothermal snowpack, $P e>1$ is unlikely in nature because of the following: (1) low density snow, which always has a very low strength, will be destroyed due to the high airflow velocity; (2) Pe depends on the temperature due to changing diffusivity. Seasonal temperature fluctuations of -60 to $-30^{\circ} \mathrm{C}$ are typical for surface snow layer in Antarctic regions, and lead to $P e$ variations of up to $25 \%$. Theoretically, $P e \approx 1.2$ could be realistic at $-60^{\circ} \mathrm{C}$ for a superficial velocity of $\approx 0.06 \mathrm{~m} \mathrm{~s}^{-1}$ (experiment "sa4"). However, simulations by Neumann (2003) showed a rapid decrease of the airflow velocity inside the snow layer $\left(\leq 0.01 \mathrm{~m} \mathrm{~s}^{-1}\right)$ for a high wind speed $\left(\approx 10 \mathrm{~m} \mathrm{~s}^{-1}\right)$ above the snow surface (pore size $\approx 1 \mathrm{~mm}$ ). This leads to a maximum $P e \approx 0.8$; (3) $P e>1$ would be possible for depth hoar (Alley et al., 1990) or kinetic growth crystals, like sublimation crystals (Gallet et al., 2014, Adams and Walter, 2014) close to the surface but they were only formed under light winds conditions. According to the reported Beaufort number (in Alley et al., 1990), this will be a maximum wind speed of $\approx 2-3 \mathrm{~m} \mathrm{~s}^{-1}$ (see also Gallet et al., 2014) above the surface. In addition, they were developed in the slopes of older dunes, leading to an additional decrease of the actual wind speed $\left(\approx 1 \mathrm{~m} \mathrm{~s}^{-1}\right)$ above the layers. Based on the simulations of Neumann (2003) an airflow velocity inside the snow layer of $\leq 0.002 \mathrm{~m} \mathrm{~s}^{-1}$ would be realistic. To reach a Peclet number $>1$ under this condition, the mean pore size must be at least $10 \mathrm{~mm}$, which would be a very extreme case for depth hoar or the kinetic growth crystals formed close to the surface. Additionally, Adams and Walters (2014) showed that the top layer of such kinetic growth crystals consists of long slender needle 


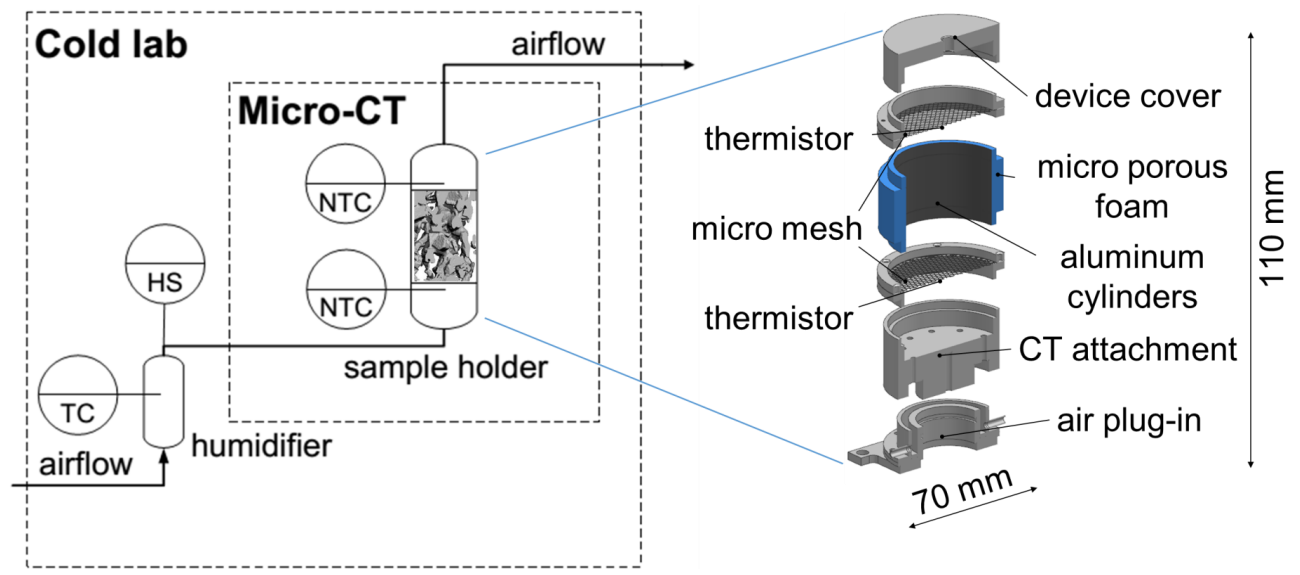

Figure 1. Schematic of the experimental setup and the sample holder. A thermocouple (TC) and a humidifier sensor (HS) inside the humidifier measured the airflow conditions. Two thermistors (NTC) close to the snow surface measured the inlet and outlet temperature of the airflow (Ebner et al., 2014).

Table 1. Morphological and flow characteristics of the experiments: volume flow $(\dot{V})$, corresponding Peclet number $(P e)$, Reynolds number $(R e)$, initial superficial velocity in snow $\left(u_{\mathrm{D}, 0}\right)$, initial snow density $\left(\rho_{0}\right)$, initial porosity $\left(\varepsilon_{0}\right)$, specific surface area $\left(\mathrm{SSA}_{0}\right)$, initial pore diameter $\left(d_{\mathrm{p}}\right)$, temperature in the cold laboratory $\left(T_{\mathrm{lab}}\right)$, and the sintering time of the snow.

\begin{tabular}{lcccccccccc}
\hline Name & $\begin{array}{c}\dot{V} \\
\mathrm{~L} \mathrm{~min}^{-1}\end{array}$ & $\begin{array}{c}P e \\
-\end{array}$ & $\begin{array}{c}R e \\
-\end{array}$ & $\begin{array}{c}u_{\mathrm{D}, 0} \\
\mathrm{~m} \mathrm{~s}^{-1}\end{array}$ & $\begin{array}{c}\rho_{0} \\
\mathrm{~kg} \mathrm{~m}^{-3}\end{array}$ & $\begin{array}{c}\varepsilon_{0} \\
-\end{array}$ & $\begin{array}{c}\mathrm{SSA}_{0} \\
\mathrm{~m}^{2} \mathrm{~kg}^{-1}\end{array}$ & $\begin{array}{c}d_{\mathrm{p}} \\
\mathrm{mm}\end{array}$ & $\begin{array}{c}T_{\text {lab }} \\
{ }^{\circ} \mathrm{C}\end{array}$ & Sintering time \\
\hline sa1 & - & - & - & - & 229.25 & 0.75 & 46.6 & 0.22 & -8.0 & 13 days at $-15^{\circ} \mathrm{C}$ \\
sa2 & 0.36 & 0.05 & 0.07 & 0.004 & 201.74 & 0.78 & 43.7 & 0.27 & -8.0 & 13 days at $-15^{\circ} \mathrm{C}$ \\
sa3 & 3.0 & 0.47 & 0.6 & 0.04 & 320.95 & 0.65 & 28.7 & 0.24 & -15.0 & 27 days at $-5^{\circ} \mathrm{C}$ \\
sa4 & 5.0 & 0.85 & 1.1 & 0.06 & 265.93 & 0.71 & 28.0 & 0.29 & -15.0 & 27 days at $-5^{\circ} \mathrm{C}$ \\
\hline
\end{tabular}

crystals connected in a cross-hatch pattern which has a low strength and will be destroyed by such a strong flow.

The acceleration voltage in the X-ray tube was $70 \mathrm{kV}$, with an intensity of $114 \mu \mathrm{A}$, and a nominal resolution of $18 \mu \mathrm{m}$. The samples were scanned with 2000 projections per 360 degree, with an integration time of $200 \mathrm{~ms}$ per projection, taking $1.5 \mathrm{~h}$ per scan. The innermost $36.9 \mathrm{~mm}$ of the total $53 \mathrm{~mm}$ diameter were scanned, and subsamples with a dimension of $7.2 \mathrm{~mm} \times 7.2 \mathrm{~mm} \times 7.2 \mathrm{~mm}$ were extracted for further processing. Absolute $z$ position varied up to a maximum of 50 voxels between subsequent scans due to the weight of the sample holder. To correct for the $z$ position, a linear encoder was built into the micro-CT. A $3 \times 3 \times 3$ median filter and Gaussian filter $(\sigma=1.4$, support $=3$ ) was applied to the reconstructed images. Otsu's method (Otsu, 1979) was used to automatically perform clustering-based image thresholding to segment the grey-level images into the ice and air phases. Morphological properties in the two-phase system were determined based on the geometry obtained by the micro-CT. The segmented data were used to calculate a triangulated ice matrix surface and tetrahedrons inscribed into the ice structure. Morphological parameters such as porosity $(\varepsilon)$ and specific surface area (SSA) were then calculated. The opening size distribution with spherical structuring elements on the micro-CT scans was used to estimate the mean pore size $\left(d_{\mathrm{p}}\right)$ (Haussener et al., 2012). The effective permeability was calculated using the finite volume technique CFD (computational fluid dynamics simulation software from ANSYS; ANSYS, 2010) by solving the continuity and Navier-Stokes equations (Zermatten et al., 2011, 2014) for laminar flow

$\nabla p=-\frac{\mu}{K} u_{\mathrm{D}}-F \rho u_{\mathrm{D}}^{2}-\frac{\gamma \rho^{2}}{\mu} u_{\mathrm{D}}^{3}$,

where $p$ is the pressure, $\mu$ is the dynamic viscosity of the fluid and $u_{\mathrm{D}}$ its superficial velocity, $\rho$ is the fluid density, $K$ is the permeability, $F$ is the Dupuit-Forchheimer coefficient, and $\gamma$ is a dimensionless factor. The first term is the result of viscous effects, predominant at low velocities, whereas the second and third terms describe the inertial effects, which become important at higher fluid velocities. As the viscous effect was still the dominant case $(R e \approx 1)$ in the experiment, only permeability $K$ was considered for further discussions. A grid convergence study based on the pressure drop (Zermatten et al., 2014) was carried out to find the optimal representative elementary volume (REV) $(6.0 \mathrm{~mm} \times 6.0 \mathrm{~mm} \times 3.0 \mathrm{~mm})$. An in-house tetrahedron-based mesh generator (Friess et al., 2013) was used to create the 
computational grid on the segmented data. The computational domain consisted of a square duct containing a sample of snow. The boundary conditions consisted of uniform inlet velocity, temperature and outlet pressure, constant wall temperature at the solid-fluid interface, and symmetry of the sample at the lateral duct walls. The square duct was 5 times the length of the sample to ensure a fully developed velocity profile at the entrance of the snow sample (Fig. 2). The largest mesh element length was $0.153 \mathrm{~mm}$, and the smallest possible mesh element measured $9.56 \mu \mathrm{m}$, with average 60 million volume elements for each segmented snow sample.

\section{Results and discussion}

The discussions of the observed results are only based on the investigated volume. Influences of the flow on the base, top and lateral boundaries of the overall sample were not considered due to lack of structural observations.

A representative temporal temperature profile of the snow sample for both laboratory temperatures of $T_{\mathrm{lab}}=-8$ and $-15^{\circ} \mathrm{C}$ is shown in Fig. 3. Variations in temperature up to 1.7 and $1.4{ }^{\circ} \mathrm{C}$ were due to heat dissipated by the $\mathrm{X}$ ray tube and temperature fluctuations inside the cold laboratory (Ebner et al., 2014). A longer sintering duration at $-5^{\circ} \mathrm{C}$ of the snow for experiment "sa3" and "sa4" was used to increase the mean thickness of the ice matrix. This avoided the destruction of the snow structure due to shear stresses caused by the airflow. The structural analysis of the snow samples was conducted on the complete tomography domain $(7.2 \mathrm{~mm} \times 7.2 \mathrm{~mm} \times 7.2 \mathrm{~mm})$. A smaller subset of $110 \times 42 \times 110$ voxels $(2 \mathrm{~mm} \times 0.75 \mathrm{~mm} \times 2 \mathrm{~mm})$ was selected to visualize the 3 -D evolution (Fig. 4). It showed no significant change in the grain shape, even for different airflow velocities, and only a slight rounding and coarsening was seen for experiments "sa1" and "sa2". A strong translation effect due to settling of sub-layering snow was visible for "sal" and "sa2". The initial ice matrix did not change with time; only coarsening processes on the ice grain surface were observed (Fig. 5). Sublimation of 4.5 and $4.9 \%$ of the ice matrix and deposition of 4.1 and $5.9 \%$ on the ice matrix were observed for "sa3" and "sa4" (Fig. 6). The data were extracted by superposition of vertical cross-sections at 0 and $96 \mathrm{~h}$ with an uncertainty of $6 \%$. The mass sublimated preferentially at locations of the ice grain with low radii due to Kelvin-effect and was relocated on the grain leading to a smoothing of the ice grain. Our observed results were supported by the vapourpressure map simulated by Brzoska et al. (2008) and the applied airflow velocity did not affect the relocation process.

The well-sintered snow showed very little settling under its own weight (Kaempfer and Schneebeli, 2007) and, consequently, no significant change in porosity was observed. This supports the hypothesis that further densification is limited by coarsening kinetics (Kaempfer and Schneebeli, 2007;

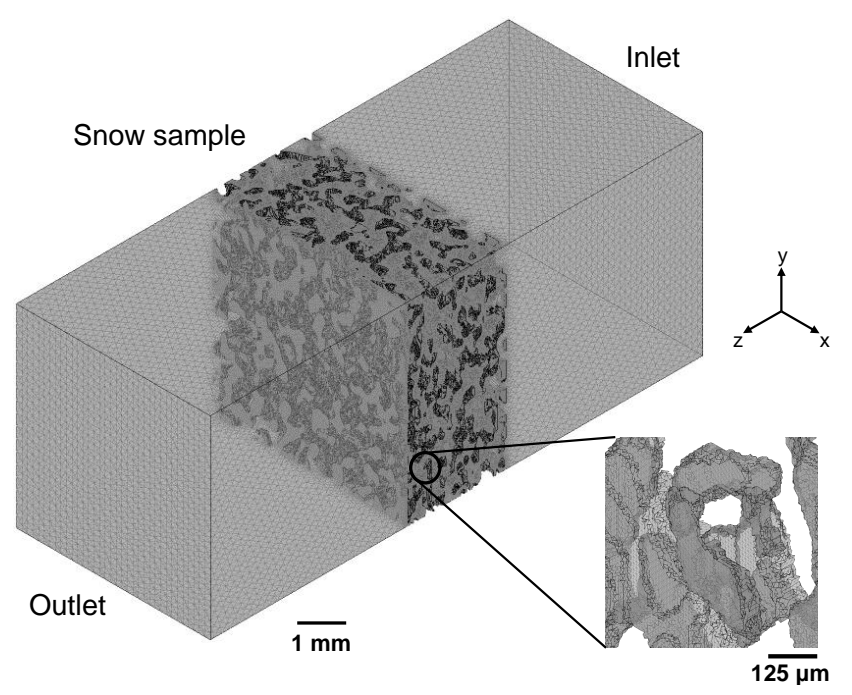

Figure 2. Schematic of the computational domain with an enlarged subsample of snow. In the snow sample, the dark gray part represents the ice, whereas the mesh is built in the pore space.

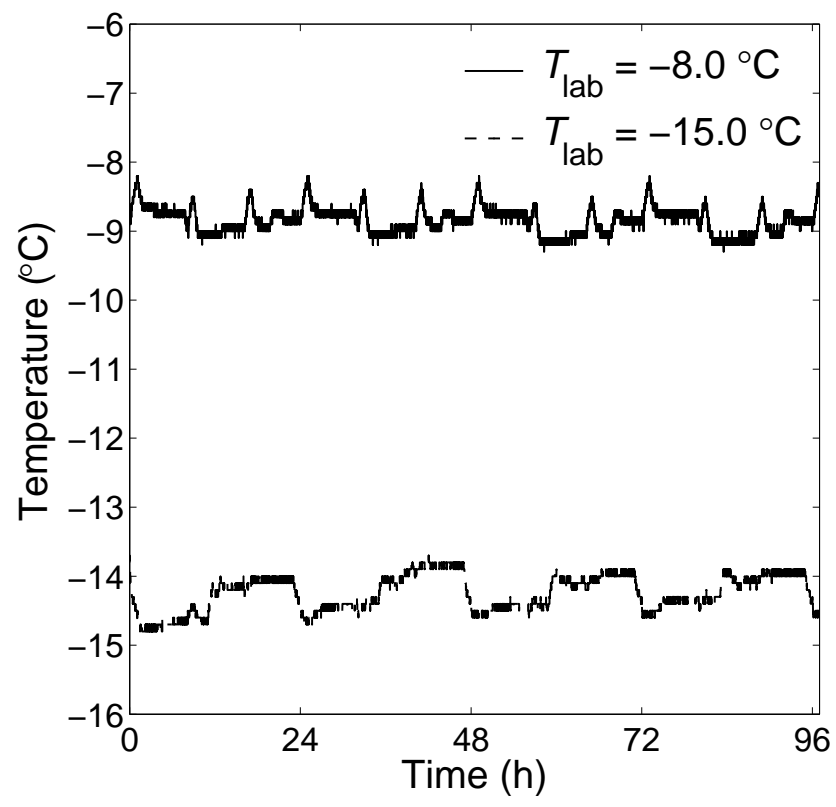

Figure 3. A typical temperature profile for experiment "sa1", "sa2" and "sa3", "sa4". The temperature rise was caused by the X-ray tube and fluctuations inside the cold laboratory (Ebner et al., 2014). The accurateness of the isothermal conditions between the top and base of the sample throughout the experiment is less than $0.2^{\circ} \mathrm{C}$ which is still in the uncertainty of the thermistors $\pm 0.2 \mathrm{~K}$ (Ebner et al., 2014).

Schleef and Löwe, 2013). A spatially constant porosity distribution at $t=0$ and $t=4$ days is seen in Fig. 7. Thus, spatial change in the flow field due to different interfacial velocities can be neglected. Consequently, $P e$ was constant with time, and therefore the advective and diffusive mass transfer 


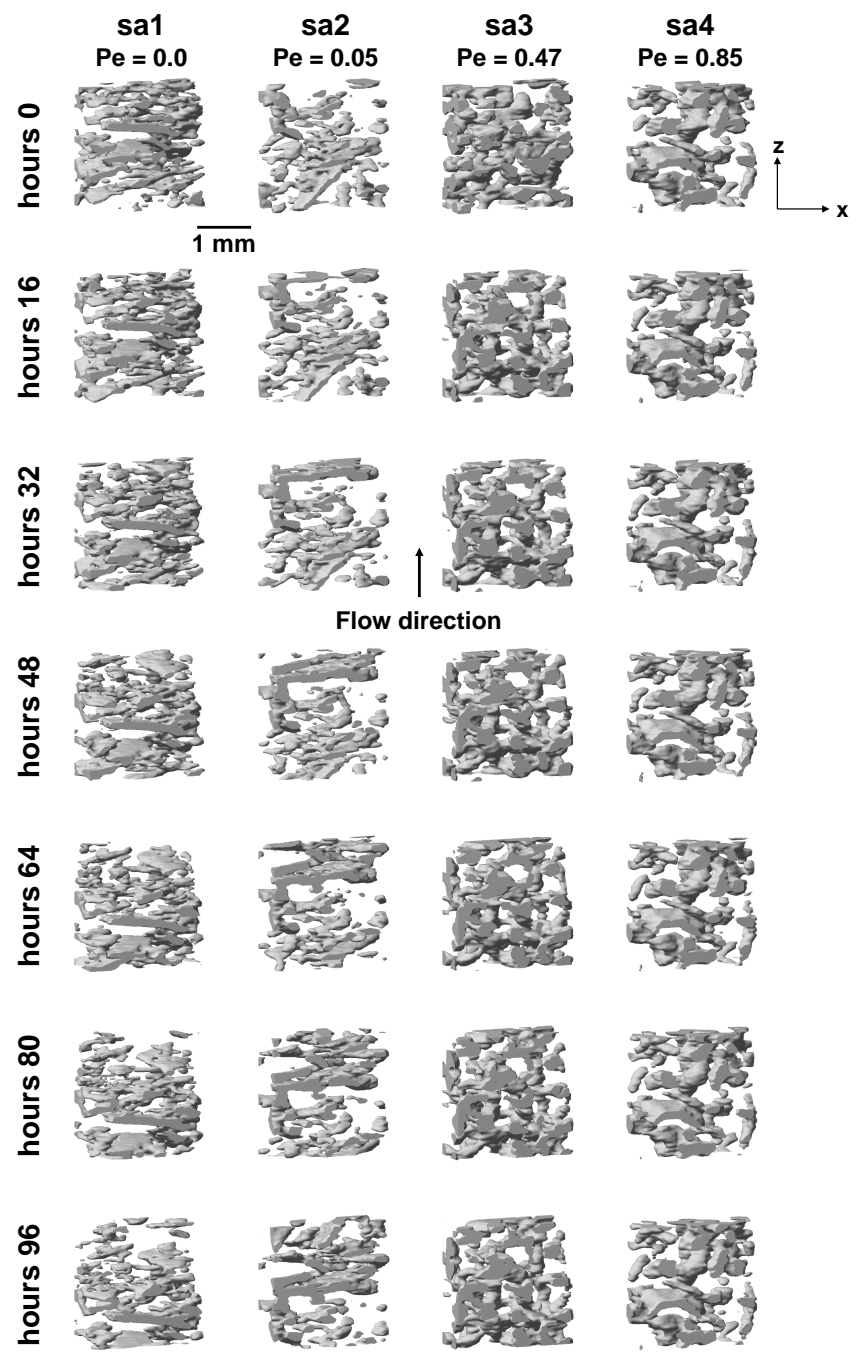

Figure 4. Evolution of the 3-D structure of the ice matrix during isothermal metamorphism under advective conditions. Experimental conditions (from left to right) at different measurement times from beginning to the end (top to bottom) of the experiment. The shown cubes are $110 \times 42 \times 110$ voxels $(2 \mathrm{~mm} \times 0.75 \mathrm{~mm} \times 2 \mathrm{~mm})$ large.

regime. The average deviation between $t=0$ and $t=4$ days was $0.5,1.8,0.5$, and $0.5 \%$ for "sa1", "sa2", "sa3" and "sa4".

Our segmented 3-D data accurately reproduced the original snow sample and the temporal porosity distribution confirmed that no settling and densification occurred in the investigated volume (Fig. 8). The gravimetric porosity $\varepsilon_{\text {grav }}$ at the beginning and at the end of each experiment was measured by weighing. The measured density values were converted to porosity $\left(\varepsilon_{\text {grav }}=1-\rho_{\mathrm{s}} / \rho_{\text {ice }}\right)$, and compared to the value of porosity computed by DPLS on the micro-CT geometry. The computed values differed from the measured ones by 1.4 and $0.1 \%$ at the beginning and 4.1 and $2.3 \%$ at the end for experiments "sa3" and "sa4". (a)

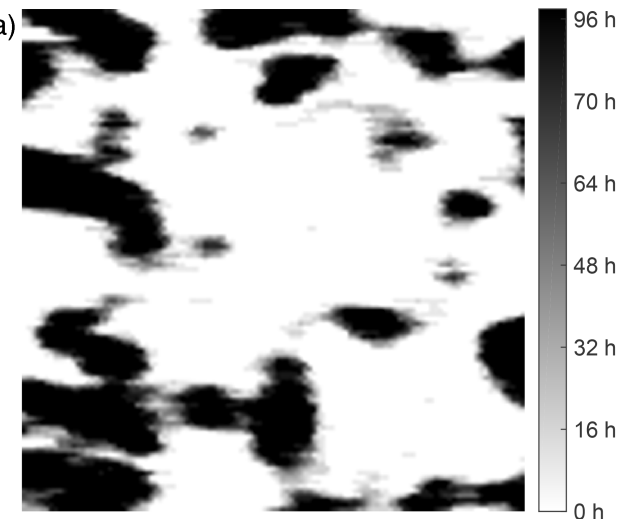

(b)

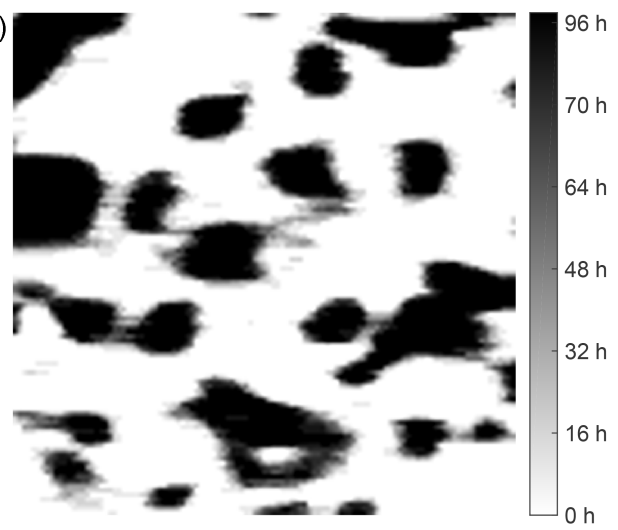

Figure 5. Residence time of ice particles within in a slice $(5.7 \mathrm{~mm} \times$ $5.7 \mathrm{~mm}$ ) parallel to the flow direction for (a) "sa3" and (b)) "sa4" by overlapping time-lapse tomography pictures. The period of $8 \mathrm{~h}$ was sufficiently short to calculate the residence time of each ice voxel with an uncertainty of $6 \%$.
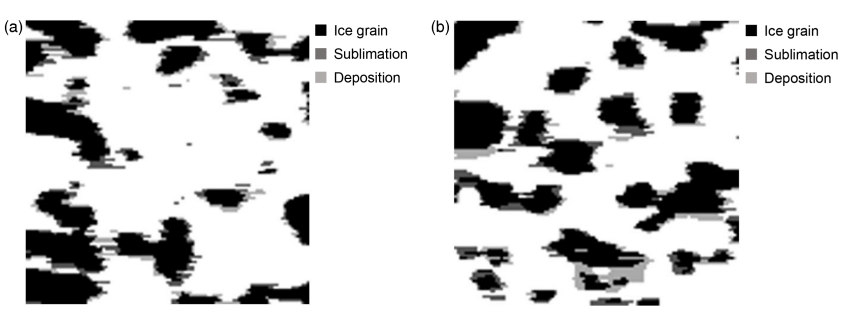

Figure 6. Superposition of vertical cross-section parallel to the flow direction at time 0 and $96 \mathrm{~h}$ for (a) "sa3" and (b) "sa4". Sublimation and deposition of water vapour on the ice grain were visible with an uncertainty of $6 \%$.

The qualitative progression of the spatial SSA of the scanned snow height for four discs of $7.2 \mathrm{~mm} \times 7.2 \mathrm{~mm} \times$ $1.8 \mathrm{~mm}$ (Fig. 9) did not change significantly with height. This suggested that the snow properties were homogeneous throughout the sample and duration of the experiments. The slight decrease of the spatial SSA for experiment "sa4" is explained by the distribution not initially being completely homogeneous. 


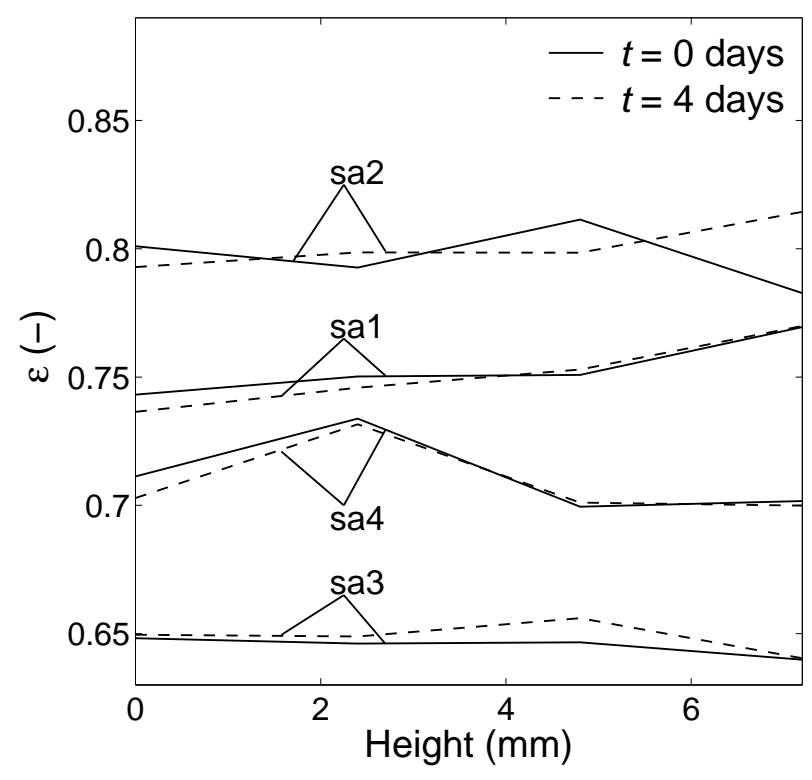

Figure 7. Spatial porosity profile of the scanned area at the beginning and at the end of each experiment. The spatial variability within the reconstructed volume was measured in four discs of $7.2 \mathrm{~mm} \times 7.2 \mathrm{~mm} \times 1.8 \mathrm{~mm}$.

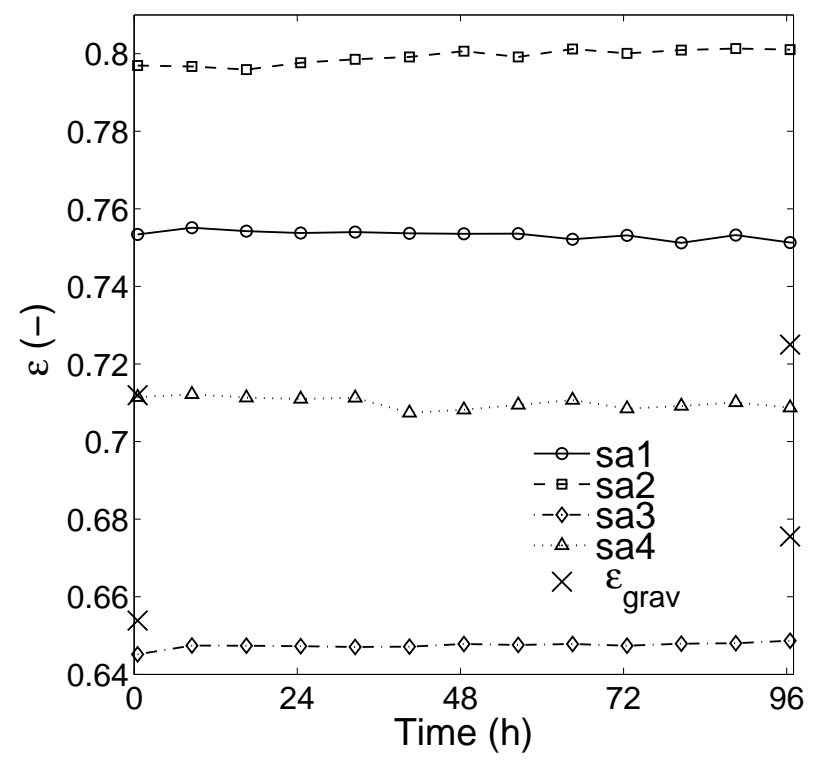

Figure 8. Evolution of the porosity over time obtained by triangulated structure surface method and the measured gravimetric density ( $\left.\varepsilon_{\text {grav }}\right)$ at the beginning and at the end of "sa3" and "sa4".

The coarsening process led to a decrease of the SSA over time (Fig. 10), which was higher for group "sa1" and "sa2" compared to "sa3" and "sa4". The difference was caused by the $34 \%$ lower initial SSA of group "sa3" and "sa4". Applying the theories developed by Legagneux et al. (2004) and Legagneux and Domine (2005), the evolution of SSA of the ice matrix could be modelled well. The model proposed is

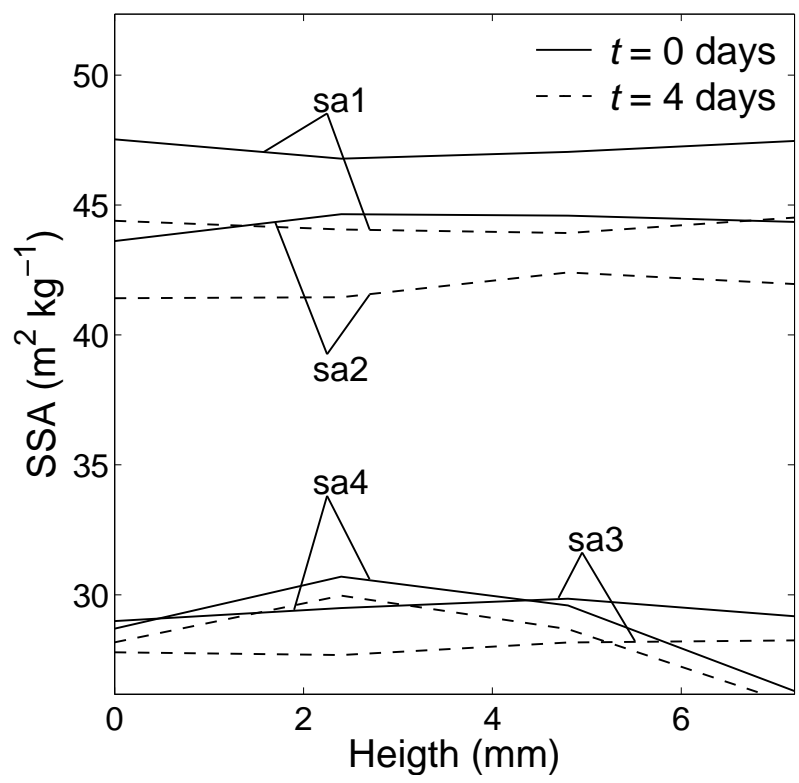

Figure 9. Spatial SSA profile of the scanned area at the beginning and at the end of each experiment. The spatial variability within the reconstructed volume was measured in four discs of $7.2 \mathrm{~mm} \times$ $7.2 \mathrm{~mm} \times 1.8 \mathrm{~mm}$.

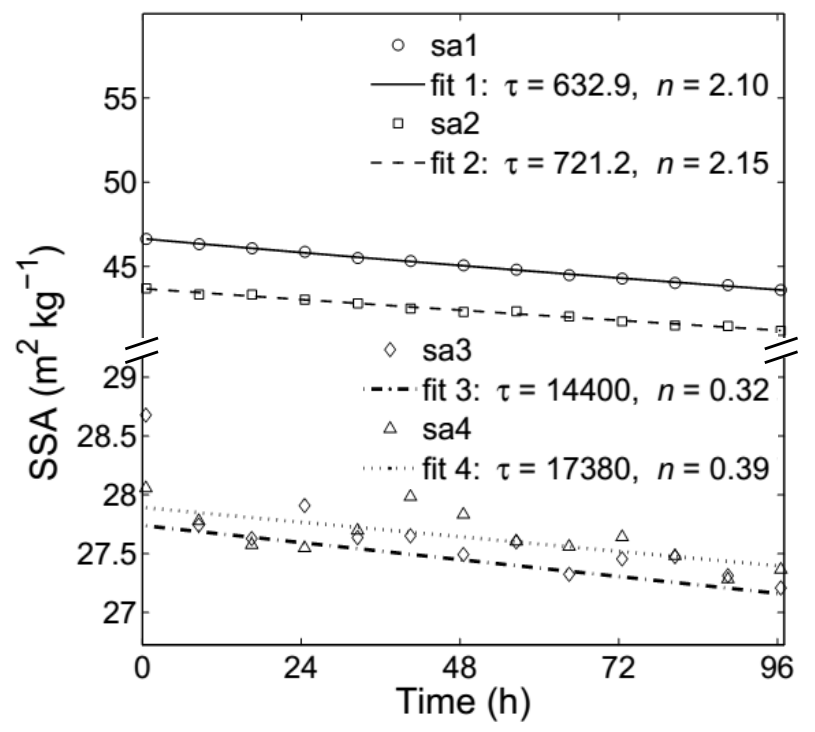

Figure 10. Temporal evolution of the specific surface area, SSA, of the ice matrix obtained by triangulated structure surface method. The computed fit is of the form $\operatorname{SSA}(t)=\operatorname{SSA}_{0}\left(\frac{\tau}{\tau+t}\right)^{1 / n}$.

given by Legagneux and Domine (2005)

$\operatorname{SSA}=\operatorname{SSA}_{0}\left(\frac{\tau}{\tau+t}\right)^{1 / n}$

where $\mathrm{SSA}_{0}$ is the initial SSA at time $t=0, n$ is the growth exponent, and $\tau$ a parameter related to grain growth and a form factor. Table 2 shows the fitted parameters and the cor- 
Table 2. Values of the fitted growth rate $\tau$ and growth exponent $n$ for the evolution of the SSA and the corresponding normalized root mean square error (NRMSE).

\begin{tabular}{lcccc}
\hline Name & $\begin{array}{c}\mathrm{SSA}_{0} \\
\mathrm{~m}^{2} \mathrm{~kg}^{-1}\end{array}$ & $\begin{array}{c}\tau \\
-\end{array}$ & $\begin{array}{c}n \\
-\end{array}$ & $\begin{array}{c}\text { NRMSE } \\
-\end{array}$ \\
\hline sa1 & 46.7 & 632.9 & 2.10 & 0.01 \\
$\mathrm{sa} 2$ & 43.6 & 721.2 & 2.15 & 0.04 \\
$\mathrm{sa} 3$ & 27.8 & 14400 & 0.32 & 0.14 \\
$\mathrm{sa} 4$ & 27.8 & 17380 & 0.39 & 0.21 \\
\hline
\end{tabular}

responding normalized root mean square error (NRMSE) for each experiment. Equation (2) fits the data of each experiment well with an average NRMSE $<0.21$. The computed fit of the SSA is shown in Fig. 10. Equation (2) gives a very qualitative estimation on the real mechanism occurring in the snow. This model is based on the physical processes involved in Ostwald ripening (Ratke and Voorhees, 2002). Ostwald ripening describes the coarsening of solid particles with a given size distribution, considering disconnected grains that do not undergo settling. The driving force in the model is the reduction of the SSA and the model hypothesis is based on the concept that mass transfer occurs by sublimation due to curvature effects, transport through the gas phase and deposition. Theoretically, the growth exponent $n$ is approximately 2 when surface processes are rate limiting and 3 when diffusion is rate limiting. Experiment "sa1" and "sa2" had a higher value of $n$, indicating a strong coarsening process due to sintering and that surface processes were rate limiting (Legagneux et al., 2004; Legagneux and Domine, 2005). Experiment "sa1" and "sa2", and "sa3" and "sa4" had similar fitting parameters and a low value of $n$, suggesting that surface effects were rate limiting (Legagneux et al., 2004; Legagneux and Domine, 2005). The lower value of $n$ for experiment "sa3" and "s4" was due to the longer sintering time of 27 days at $-5^{\circ} \mathrm{C}$ before the experiments were started leading to a very little change in the microstructure of the snow. When the sintering times of 13 and 27 days were included in the model, the fitting parameters indicated a consistent growth exponent $n$ for each experiment (Table 3 ) and a good agreement with the theory. They expressed strong coarsening and surface processes for each experiment. Notice, Eq. (2) extremely depends on the initial state, which is well illustrated by the large difference obtained for $n$ values of "sa3" and "sa4" between Tables 2 and 3. Concluding, the calculated values indicated that surface processes caused the limiting rate rather than the diffusion step and no significant influence of advective transport could be observed.

The effect of decreasing SSA on the permeability was not elucidated in our experiments. A SSA decrease of at least $5 \%$ in the experiments could not be reproduced in the permeability. However, the computational uncertainty up to $16 \%$ (Zermatten et al., 2014) in the permeability is still in the range
Table 3. Values of the fitted growth rate $\tau$ and growth exponent $n$ for the evolution of the SSA including the sintering time of 13 and 27 days, and the corresponding normalized root mean square error (NRMSE).

\begin{tabular}{lcccc}
\hline Name & $\begin{array}{c}\mathrm{SSA}_{0} \\
\mathrm{~m}^{2} \mathrm{~kg}^{-1}\end{array}$ & $\begin{array}{c}\tau \\
-\end{array}$ & $\begin{array}{c}n \\
-\end{array}$ & $\begin{array}{c}\text { NRMSE } \\
-\end{array}$ \\
\hline $\mathrm{sa} 1$ & 64.4 & 320.9 & 2.10 & 0.01 \\
$\mathrm{sa} 2$ & 56.8 & 409.1 & 2.15 & 0.04 \\
$\mathrm{sa} 3$ & 34.5 & 1229 & 2.0 & 0.15 \\
$\mathrm{sa} 4$ & 36.0 & 1063 & 1.91 & 0.27 \\
\hline
\end{tabular}

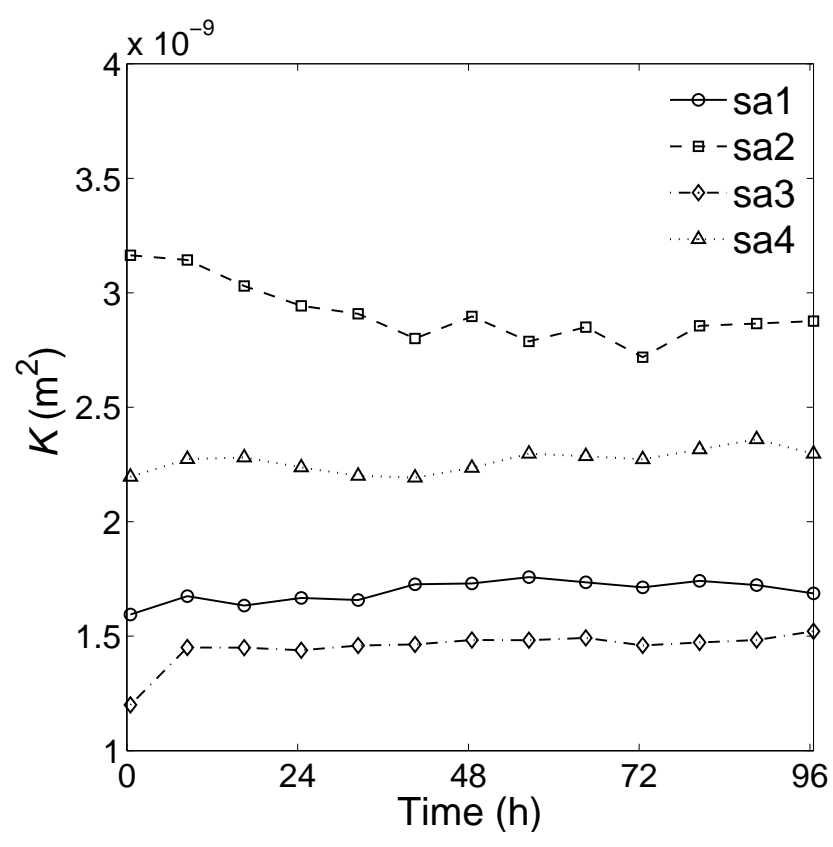

Figure 11. Temporal evolution of the effective permeability by applying DPLS with an uncertainty of $16 \%$ (Zermatten et al., 2014).

to cover the correlation between SSA and permeability. The effect of increasing airflow velocity had no influence on the flow characteristics (Fig. 11). The temporal evolution of permeability for experiment "sa2" showed a decrease of $8 \%$ for the first $40 \mathrm{~h}$ and remained constant afterwards. Experiments "sa1", "sa3" and "sa4" showed no significant change in the permeability, which is consistent with the negligible change in density. The average fluctuations of the permeability $K$ between each time step and the slight decrease at the beginning in "sa2" showed small differences that were below the precision of the numerical method with an uncertainty up to $16 \%$ (Zermatten et al., 2014). Only the first time step of "sa3" showed a particularly high difference of $17.3 \%$, but neither the porosity nor SSA showed significant differences reflecting this value. This difference could therefore be due to an error during the measurement or during the meshing procedure. 


\section{Summary and conclusions}

Four isothermal metamorphism experiments of snow under saturated advective airflow were performed, each with duration of 4 days. The effects of the main transport processes, diffusion and advection, were analysed inside the pore space. The airflow velocities were chosen based on the Peclet number. $P e>0.85$ for natural surface conditions were not possible due to the destruction of the snow structure and is not frequent in natural snowpacks due to the low airflow velocities in snow (Neumann, 2003; Colbeck, 1997b). Every $8 \mathrm{~h}$ the snow microstructure was observed by X-ray micro-tomography. The micro-CT scans were segmented, and porosity and specific surface area were calculated. Effective permeability was calculated in direct pore-level simulations (DPLS) to analyse the flow characteristic.

The experimental observations supported the hypothesis that further densification was limited by coarsening kinetics and further confirmed a constant porosity evolution (Kaempfer and Schneebeli, 2007). Curvature caused sublimation of small ice grains and ice structures with small curvature radii leading to a slight decrease in SSA. Compared to rates typical for isothermal snow metamorphism, no enhancement of mass transfer inside the pores of isothermal advection with saturated air was observed. Sublimation deposition caused by the Kelvin effect was the limiting factor independently of the transport regime in the pores.

Acknowledgements. The Swiss National Science Foundation granted financial support under project Nr. 200020-146540. The authors thank M. Jaggi and S. Grimm for technical support with the measurements and Frédéric Flin for thorough and constructive review, which contributed to the quality of our paper.

Edited by: F. Dominé

\section{References}

Adams, E. E. and Walters, D. J: Fine structure layering in radiation recrystallized snow, International Snow Science Workshop, Proceedings, Banff, Canada, 29 September-3 October 2014, 8 pp., 2014.

Albert, M. R.: Numerical experiments on firn ventilation with heat transfer, Ann. Glaciol., 18, 161-165, 1993.

Albert, M. R. and Mc Gilvary, W. R.: Thermal effects due to air flow and vapour transport in dry snow, J. Glaciol., 38, 274-281, 1992.

Albert, M. R., Shuman, C., Courville, Z., Bauer, R., Fahnestock, M., and Scambos, T.: Extreme firn metamorphism: impact of decades of vapor transport on near-surface firn at a low-accumulation glazed site on the east Antarctic plateau, Ann. Glaciol., 39, 7378, 2004.

Alley, R. B., Saltzman, E. S., Cuffey, K. M., and Fitzpatrick, J. J.: Summertime formation of Depth Hoar in central Greenland, Geophys. Res. Lett., 17, 2393-2396, 1990.

ANSYS: ANSYS CFX, ANSYS, Inc., Canonsburg, PA, USA, 2010.
Arnaud, L., Lipenkov, V., Barnola, J., Gay, M., and Duval, P.: Modelling of the densification of polar firn: characterization of the snow-firn transition, Ann. Glaciol., 26, 39-44, 1998.

Bader, H., Haefeli, R., Bucher, E., Neher, J., Eckel, C., and Thams, C.: Der Schnee und seine Metamorphose, Beitr. Geol. Schweiz, Geotechn. Ser.-Hydrol., 3, 1-313, 1939.

Brzoska, J.-B., Flin, F., and Barckicke, J.: Explicit iterative computation of diffusive vapour field in the 3-D snow matrix: preliminary results for low flux metamorphism, Ann. Glaciol., 48, 13-18, 2008.

Chen, S. and Baker, I.: Evolution of individual snowflakes during metamorphism, J. Geophys. Res., 115, 1-9, 2010.

Clifton, A., Manes, C., Rüedi, J.-D., Guala, M., and Lehning, M.: On shear-driven ventilation of snow, Bound.-Lay. Meteorol., 126, 249-261, 2008.

Colbeck, S. C.: Thermodynamics of snow metamorphism due to variations in curvature, J. Glaciol., 26, 291-301, 1980.

Colbeck, S. C.: Air movement in snow due to wind-pumping, J. Glaciol., 35, 209-213, 1989.

Colbeck, S. C.: A review of sintering in seasonal snow, Technical Report, 97-10, Cold Regions Research \& Engineering Laboratory, Hanover, New Hampshire, 1997a.

Colbeck, S. C.: Model of wind pumping for layered snow, J. Glaciol., 43, 60-65, 1997b.

Colbeck, S. C.: Sintering in a dry snow cover, J. Appl. Phys., 84, 4585-4589, 1998.

Colbeck, S. C.: Sintering of unequal grains, J. Appl. Phys., 89, 4612-4618, 2001.

Cunningham, J. and Waddington, E. D.: Air flow and dry deposition of non-sea salt sulphate in polar firn: paleoclimatic implications, Atmos. Environ., 27A, 2943-2956, 1993.

Domine, F., Albert, M., Huthwelker, T., Jacobi, H.-W., Kokhanovsky, A. A., Lehning, M., Picard, G., and Simpson, W. R.: Snow physics as relevant to snow photochemistry, Atmos. Chem. Phys., 8, 171-208, doi:10.5194/acp-8-171-2008, 2008.

Ebner, P. P., Grimm, S. A., Schneebeli, M., and Steinfeld, A.: An instrumented sample holder for time-lapse microtomography measurements of snow under advective airflow, Geosci. Instrum. Method. Data Syst., 3, 179-185, doi:10.5194/gi-3-1792014, 2014.

Fierz, C., Armstrong, R. L., Durand, Y., Etchevers, P., Greene, E., McClung, D. M., Nishimura, K., Satyawali, P. K. and Sokratov, S. A.: The International Classification for Seasonal Snow on the Ground, IHP-VII Technical Documents in Hydrology No. 83, IACS Contribution No. 1, UNESCO-IHP, Paris, 2009.

Friess, H., Haussener, S., Steinfeld, A., and Petrasch, J.: Tetrahedral mesh generation based on space indicator functions, Int. J. Numer. Meth. Eng., 93, 1040-1056, 2013.

Gallet, J.-C., Domine, F., Savarino, J., Dumont, M., and Brun, E.: The growth of sublimation crystals and surface hoar on the Antarctic plateau, The Cryosphere, 8, 1205-1215, doi:10.5194/tc-8-1205-2014, 2014.

German, R. M.: Sintering Theory and Practive, John Wiley, New York, 1996.

Gjessing, Y. T.: The filtering effect of snow, in: Isotopes and Impurities in Snow and Ice Symposium, edited by: Oeschger, H., Ambach, W., Junge, C. E., Lorius, C., and Serebryanny, L., IASHAISH Publication, Dorking, 118, 199-203, 1977. 
Grannas, A. M., Jones, A. E., Dibb, J., Ammann, M., Anastasio, C., Beine, H. J., Bergin, M., Bottenheim, J., Boxe, C. S., Carver, G., Chen, G., Crawford, J. H., Dominé, F., Frey, M. M., Guzmán, M. I., Heard, D. E., Helmig, D., Hoffmann, M. R., Honrath, R. E., Huey, L. G., Hutterli, M., Jacobi, H. W., Klán, P., Lefer, B., McConnell, J., Plane, J., Sander, R., Savarino, J., Shepson, P. B., Simpson, W. R., Sodeau, J. R., von Glasow, R., Weller, R., Wolff, E. W., and Zhu, T.: An overview of snow photochemistry: evidence, mechanisms and impacts, Atmos. Chem. Phys., 7, 4329-4373, doi:10.5194/acp-7-4329-2007, 2007.

Haussener, S., Gergely, M., Schneebeli, M., and Steinfeld, A.: Determination of the macroscopic optical properties of snow based on exact morphology and direct pore-level heat transfer modeling, J. Geophys. Res., 117, 1-20, 2012.

Hobbs, P. V. and Mason, B. J.: The sintering and adhesion of ice, Philos. Mag., 9, 181-197, 1963.

Kaempfer, T. U. and Schneebeli, M.: Observation of isothermal metamorphism of new snow and interpretation as a sintering process, J. Geophys. Res., 112, 1-10, 2007.

Kingery, W. D.: On the metamorphism of snow, in: International Geological Congress, XXI Sesion, Norden, Copenhagen, 1525 August 1960, 81-89, 1960a.

Kingery, W. D.: Regelation, surface diffusion, and ice sintering, J. Appl. Phys., 31, 833-838, 1960b.

Kuroiwa, D.: A study of ice sintering, Tellus, 13, 252-259, 1961.

Legagneux, L. and Domine, F.: A mean field model of the decrease of the specific surface area of dry snow during isothermal metamorphism, J. Geophys. Res., 110, F04011, doi:10.1029/2004JF000181, 2005.

Legagneux, L., Taillandier, A. S., and Domine, F.: Grain growth theories and the isothermal evolution of the specific surface area of snow, J. Appl. Phys., 95, 6175-6184, 2004.

Legrand, M. and Mayewski, P.: Glaciochemistry of polar ice cores: a review, Rev. Geophys., 35, 219-243, 1997.

Löwe, H., Spiegel, J. K., and Schneebeli, M.: Interfacial and structural relaxations of snow under isothermal conditions, J. Glaciol., 57, 499-510, 2011.

Maeno, N. and Ebinuma, T.: Pressure sintering of ice and its implication to the densification of snow at polar glaciers and ice sheets, J. Phys. Chem.-US, 87, 4103-4110, 1983.

McConnell, J. R., Bales, R. C., Stewart, R. W., Thompson, A. M., Albert, M. R., and Ramos, R.: Physically based modelling of atmosphere-to-snow-to-firn transfer of $\mathrm{H}_{2} \mathrm{O}_{2}$ at the South Pole, J. Geophys. Res., 103, 10561-10570, 1998.

Neumann, T. A.: Effects of Firn Ventilation on Geochemistry of Polar Snow, $\mathrm{PhD}$ thesis, University of Washington, Washington, 2003.

Neumann, T. A. and Waddington, E. D.: Effects of firn ventilation on isotopic exchange, J. Glaciol., 50, 183-194, 2004.

Neumann, T. A., Albert, M. R., Engel, C., Courville, Z., and Perron, F.: Sublimation rate and the mass transfer coefficient for snow sublimation, Int. J. Heat Mass. Tran., 52, 309-315, 2009.

Otsu, N.: A threshold selection method from gray-level histograms, IEEE T. Syst. Man. Cyb., 9, 62-66, 1979.
Pinzer, B. R. and Schneebeli, M.: Breeding snow: an instrumented sample holder for simultaneous tomographic and thermal studies, Meas. Sci. Technol., 20, 1-9, 2009.

Pinzer, B. R., Schneebeli, M., and Kaempfer, T. U.: Vapor flux and recrystallization during dry snow metamorphism under a steady temperature gradient as observed by time-lapse microtomography, The Cryosphere, 6, 1141-1155, doi:10.5194/tc-61141-2012, 2012.

Ratke, L. and Voorhees, P. W.: Growth and Coarsening, Springer, Berlin, Heidelberg, Germany, ISBN 978-3-540-42563-2, 2002.

Schleef, S. and Löwe, H.: X-ray microtomography analysis of isothermal densification of new snow under external mechanical stress, J. Glaciol., 59, 233-243, 2013.

Schleef, S., Jaggi, M., Löwe, H., and Schneebeli, M.: Instruments and methods: an improved machine to produce nature-identical snow in the laboratory, J. Glaciol., 60, 94-102, 2014.

Schneebeli, M. and Sokratov, S.: Tomography of temperature gradient metamorphism of snow and associated changes in heat conductivity, Hydrol. Process., 3665, 3655-3665, 2004.

Severinghaus, J. P., Albert, M. R., Courville, Z. R., Fahnestock, M. A., Kawamura, K., Montzka, S. A., Muehle, J., Scambos, T. A., Shields, E., Shuman, C. A., Suwa, M., Tans, P., and Weiss, R. F.: Deep air convection in the firn at a zero-accumulation site, central Antarctica, Earth Planet. Sc. Lett., 293, 359-367, 2010.

Sowers, T., Bender, M., Raynard, D., and Korotkevich, Y. S.: $\delta^{15} \mathrm{~N}$ in air trapped in polar ice: a tracer of gas transport in the firn and a possible constraint on ice age-gas age differences, J. Geophys. Res., 97, 15683-15697, 1992.

Stössel, F., Guala, M., Fierz, C., Manes, C., and Lehning, M.: Micrometeorological and morphological observations of surface hoar dynamics on a mountain snow cover, Water Resour. Res., 46, 1-11, 2010.

Sturm, M. and Johnson, J. B.: Natural convection in the subarctic snow cover, J. Geophys. Res., 96, 11657-11671, 1991.

Vetter, R., Sigg, S., Singer, H. M., Kadau, D., Herrmann, H. J., and Schneebeli, M.: Simulating isothermal aging of snow, Europhys. Lett., 89, 26001, doi:10.1209/0295-5075/89/26001, 2010.

Waddington, E. D., Cunningham, J., and Harder, S. L.: The effects of snow ventilation on chemical concentrations, in: Chemical Exchange Between the Atmosphere and Polar Snow, edited by: Wolff, E. W. and Bales, R. C., Springer, Berlin, NATO ASI Series, 43, 403-452, 1996.

Wang, X. and Baker, I.: Evolution of the specific surface area of snow during high-temperature gradient metamorphism, J. Geophys. Res. Atmos., 119, 13690-13703, 2014.

Zermatten, E., Haussener, S., Schneebeli, M., and Steinfeld, A.: Instruments and Methods: tomography-based determination of permeability and Dupuit-Forchheimer coefficient of characteristic snow samples, J. Glaciol., 57, 811-816, 2011.

Zermatten, E., Schneebeli, M., Arakawa, H., and Steinfeld, A.: Tomography-based determination of porosity, specific area and permeability of snow and comparison with measurements, Cold Reg. Sci. Technol., 97, 33-40, 2014. 